\title{
Effect of Different Strenght of Media on Germination and Seedling Growth of Tomato and Sucrose Effect on Biomass of Its Callus
}

\author{
Arkan Setiaji ${ }^{1}$, RR Rifka Annisa ${ }^{1}$, Rumiyati Rumiyati ${ }^{2}$ Endang Semiarti ${ }^{*}$ \\ ${ }^{1}$ Faculty of Biology, Universitas Gadjah Mada \\ ${ }^{2}$ Faculty of Pharmacy, Universitas Gadjah Mada \\ *email: endsemi@ugm.ac.id
}

\section{Article Info}

Keyword:

Callus

Hypocotyl

Strenght of medium

Sucrose

Tomato

\section{Article history:}

Received: 08/10/2019

Revised: $25 / 01 / 2020$

Accepted: $17 / 04 / 2020$

\begin{abstract}
Bioactive compounds of plant cell culture extracts are currently being looked at for its potential for the development of nutraceutical products. Tomato callus is known to have cytoprotective activity. The availability of explants and its callus production are two important things. This paper reports the effect of different strengths of the medium on seed germination and seedling growth of tomato $\mathrm{cv}$. Permata and sucrose effects on their biomass callus. Seeds were grown on 4 kinds of germination media. Hypocotyl was taken as explants for callus induction in Murashige \& Skoog (MS) medium supplemented with $2.0 \mathrm{mg} / \mathrm{L}$ 6-Benzylaminopurine (BA) and 0.2 $m g / L$ 1-Naphthaleneacetic acid (NAA), 3\% sucrose, and subcultured after 20 days on medium with 6 variations of sucrose. The highest values for tomato hypocotyl's height were obtained from the $1 / 2$ and $1 / 4 M S$, while the highest fresh weight was obtained from the MS O. Both the fresh weight and dry weight of the callus increased along with increasing sucrose concentration. The explant age and biomass need to be a concern regarding what kind of callus that will be produced. Application of 5\% sucrose concentration is recommended for callus production in this study.
\end{abstract}

Copyright () 2020 Universitas Islam Negeri Raden Fatah Palembang. All Right Reserved

\section{Introduction}

Skin aging has become a serious problem in the world along with deteriorating environmental quality that causing an increase of free radicals and excessive UV light exposure. The UV radiation is the most causes of skin aging with formed free radicals. It causes unsaturated lipids degradation and changes in the structure of elastins and fibrillar proteins-collagen (Miastkowska \& Sikora, 2018). Product-based on 'plant stem cells'
(PSC) extract has been innovation in cosmetics and regenerative medicine (Moruś, Baran, Rost-Roszkowska, \& Skotnicka-Graca, 2014). This term refers to callus, a wound tissue produced in response to injury that is generally made up of friable, large, and vacuolated with highly differentiated and unorganized cells (Smith, 2012). It can be used either mass of callus or cell suspension.

Schmid et al. (2008) reported that apple (Malus domestica) PSC extract can promote 
regeneration of human fibroblast cells and hair follicles which also postponed the sign of skin aging. Callus of tomato (Solanum lycopersicum) has cytoprotective activity by increasing the viability of Human Dermal Fibroblast Adult (HDFa) cells (Riastri, 2019). Both ethanolic extracts are flavonoid-rich and their aqueous extract is predicted to contain protein (19-108 $\mathrm{kDa} \mathrm{MW}$ ) that contributes to induce cell regeneration (Hana, 2016).

Optimization of the medium is one of the main aspects of the development of callusbased products. Starting from the medium for seed germination, induction, until the callus harvesting process. The most widely used of the plant culture medium is MS (Murashige \& Skoog, 1962). It has characteristics as a high salts content in medium (Kumar \& Loh, 2012), however, this nutrient of the medium is not necessarily always optimal for germination and seedling growth.

Exogenous application of cytokinin and/ or auxin induces callus in various species of plants. In the generally intermediate ratio of both could trigger callus induction (Skoog \& Miller, 1957). In addition to determining the right balance of giving PGRs, high quality of callus can be produced by manipulating nutrient components in the culture medium (e.g., nitrogen, phosphate, and carbon source) for the effective production of secondary metabolites (VanderMolen, Raja, El-Elimat, \& Oberlies, 2013). Sucrose is mainly supplied energy source for plant cells. It can be used for the reduction of potential osmotic of the culture medium and enhance the production of secondary metabolites (Naik \& Al-Khayri, 2016; Modarres, Bahabadi, \& Yazdi, 2018). Combining the effects of PGR and sucrose may provide multiple benefits for callus and its content.

The present study was performed to evaluate the effects of the strength of solid MS medium on tomato germination and seedling development and to provide an initial overview of how sucrose affects tomato callus biomass.

\section{Materials and Methods \\ Plant Materials}

Seeds of local hybrid tomato cultivar Permata were purchased from East-West Seed
Indonesia Ltd. The seeds were sterilized in $100 \%$ solution of commercial bleach containing $5.25 \% \quad(\mathrm{w} / \mathrm{v})$ of sodium hypochlorite for 5 minutes and continued with rinsing in sterile distilled water. Subsequently, the seeds were surface sterilization in $70 \%$ (v/v) ethanol for 1 minute and rinsed again (3 times for 1 minute).

The surface-sterilized seeds were transferred to the MS media of various basal strengths ( $1 / 4 \mathrm{MS}, 1 / 2 \mathrm{MS}$, and full-strength MS), and sucrose-agar (SA, 3\% of sucrose) medium and then for 10 days (tomato) grow to the seedling after the first germination. The optimal medium for seed germination will be used next for the propagation of sprouts that will be induced callus.

\section{Callus Induction}

The young hypocotyl was excised about 1 $\mathrm{cm}$ as a source of explants for callus induction in MS medium. Explants were grown on MS medium, containing $2 \mathrm{mg} / \mathrm{L} \quad 6-$ Benzylaminopurine (BA) and $0.2 \mathrm{mg} / \mathrm{L} \mathrm{1-}$ Naphthaleneacetic acid (NAA), sucrose 3\% for the next 20 days. The callus was then subcultured for the next 20 days into MS medium with variations of sucrose $(1,2,3,4$, and $5 \%$ ).

For all media used, the $\mathrm{pH}$ of the medium was adjusted to 5.6-6.3 before autoclaving $\left(121^{\circ} \mathrm{C}, 15 \mathrm{lbs}, 15\right.$ minutes. Cultures were kept in an incubation room at $24 \pm 2^{\circ} \mathrm{C}$ under continuous light conditions $(3,000$ lux, approx.).

\section{Data Analysis}

Germination index and germination rate are calculated based on the formula of EnríquezPeña et al. as follows :

where :

IG index of germination

$n_{i} \quad$ number of germinating seeds in the day $i$

$t_{i} \quad \mathrm{~d}$ after inoculation

$N \quad$ total number of seeds

$$
\mathrm{GV}=\sum \frac{\left(n_{i}\right)}{t}
$$

where :

GV germination velocity

$\mathrm{t}$ time of germination after initiating culture until germination of the last seed 
Hypocotyl biomass was also weighed on $10^{\text {th }}$ day after germination. The fresh and dry weight of callus was obtained on $20^{\text {th }}$ day for growth index calculation (3), which was also observed on the appearance of callus morphology.

$$
\mathrm{GI}=\frac{W_{f}-W_{0}}{W_{0}}
$$

where :

GI growth index

$W_{f} \quad$ final biomass

$W_{0} \quad$ initial biomass

\section{Results and Discussion}

\section{Result}

\section{Effect of different strength of medium on germination and seedling development}

Tomato seeds begin to germinate in 2 days after planting on the $4^{\text {th }}$ variation of the medium. Elongation of seedling especially in hypocotyl was observed at $4^{\text {th }}$ days on MS 0 and $1 / 2 \mathrm{MS}$ medium, and $5^{\text {th }}$ day on $1 / 4 \mathrm{MS}$ and SA media (Fig. 1). The complete opening of cotyledon leaf was observed on the $9^{\text {th }}$ day.

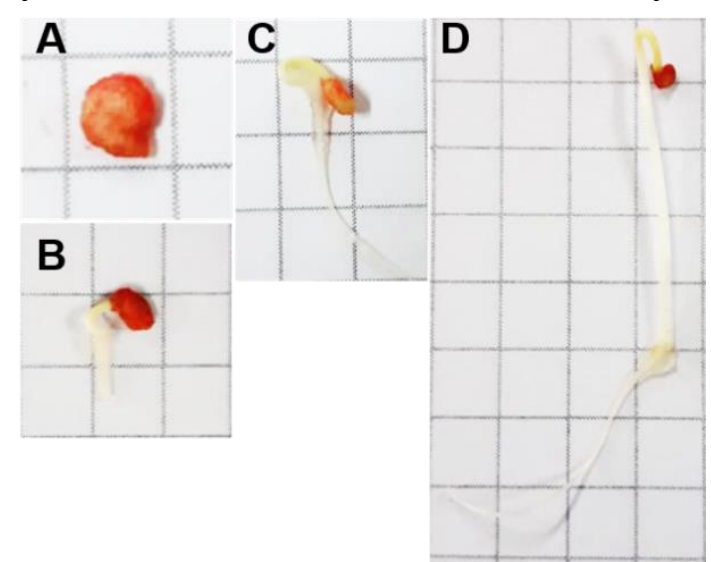

Figure 1. Morphological changes during germination of tomato. Observation on (A) 0 day; (B) $2^{\text {nd }}$ day; (C) $3^{\text {rd }}$ day; and (D) $5^{\text {th }}$ day. 1 grid = $5 \times 5 \mathrm{~mm}$

Based on Fig. 2, the percentage of seed germination reached $100 \%$ in $1 / 2$ MS medium and SA or if calculated into germination index reached 5 days and the speed of reflection, ie 6 seeds per day, $93 \%$ in MS medium $(\mathrm{IG}=4.50$ $\mathrm{d}, \mathrm{GV}=5.40$ seeds per day), and $97 \%$ in MS medium IG ( $\mathrm{IG}=4.83 \mathrm{~d}, \mathrm{GV}=5.80$ seeds per day). This percentage is above the average product quality guarantee for a minimum level of germination, which is $85 \%$ of each packaged seeds. The highest average height of hypocotyl seedlings on the $7^{\text {th }}$ day is in the medium MS $1 / 4$, which is $6.45 \pm 0.15 \mathrm{~cm}$ with results that are not significantly different from MS $1 / 2$, which is $6.30 \pm 0.18 \mathrm{~cm}$.
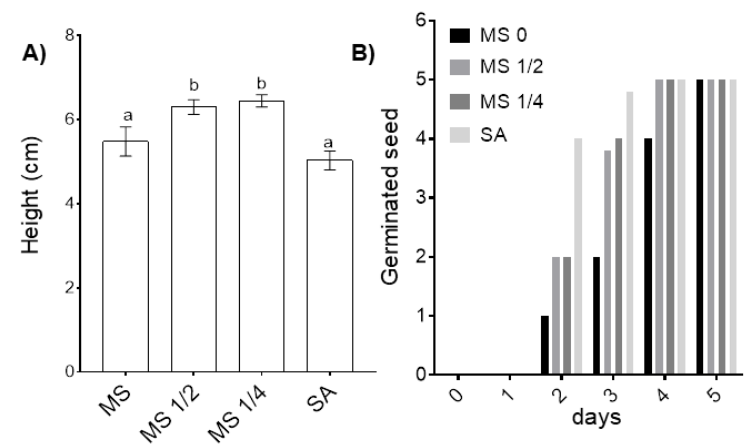

Figure 2. Effect of media variations on (a) hypocotyl height and (b) germination time

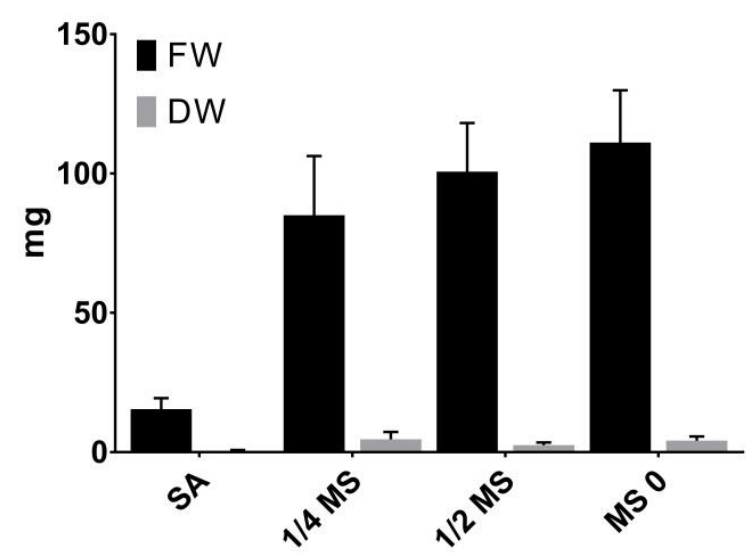

Figure 3. Effect of media variations on hypocotyl's fresh and dry weight

The performance of germination and growth of tomato seedlings varies depending on the variety and medium. When compared to other studies, for example, tomatoes treated with shaking out in vermicompost and chicken manure have increased germination to $>95 \%$ compared to controls only $85 \%$ (Arancon et al., 2012). In the tomato 'Beske' was grown in MS medium, germination only reached $57 \%$ in the $14^{\text {th }}$ day post-planted (Durosomo, Popoola, Afolabi, \& Idehen, 2014). In the tomato 'Moneymaker' grown on MS medium, the germination rate was only $69 \%$ (Chaudrhy et al., 2010).

Based on Fig. 2, the highest FW was obtained from sprouts planted on MS0 medium that reach $111.12 \pm 8.39 \mathrm{mg}$, the results were not significantly different from $1 / 2$ 
MS. Whereas in DW, the highest value obtained in the treatment $1 / 4$ MS that reach $4.64 \pm 1.18 \mathrm{mg}$, which was not significantly different from MS 0 and $1 / 2$ MS. The lightest hypocotyl in both FW and DW was obtained in the SA treatment both in $15.44 \pm 1.77 \mathrm{mg}$ and $0.08 \pm 0.40 \mathrm{mg}$.

\section{Effect of sucrose on callus}

The initiation of callus began on the $5^{\text {th }}$ day of incubation. The wound site at both ends and in the middle part of the hypocotyl form some protuberances, some of them was swollen. In general, the callus morphology was greenish, consist of compact with small of friable cells only in the outside area, and in the inside of callus can be found root/shoot nodules. The

Table 1. Tomato Callus Growth Index

\begin{tabular}{ccc}
\hline T & \multicolumn{1}{c}{ FW } & DW \\
\hline 0 & $799.74 \pm 107.55^{\mathrm{a}}$ & $0.67 \pm 0.17^{\mathrm{a}}$ \\
1 & $880.46 \pm 43.14^{\mathrm{a}}$ & $0.68 \pm 0.08^{\mathrm{a}}$ \\
2 & $933.87 \pm 100.41^{\mathrm{a}}$ & $1.31 \pm 0.32^{\mathrm{ab}}$ \\
3 & $940.34 \pm 91.08^{\mathrm{a}}$ & $1.77 \pm 0.33^{\mathrm{b}}$ \\
4 & $966.86 \pm 67.52^{\mathrm{a}}$ & $2.70 \pm 0.24^{\mathrm{c}}$ \\
5 & $1092.71 \pm 119.16^{\mathrm{a}}$ & $2.68 \pm 0.40^{\mathrm{c}}$ \\
\hline * Abbrev. T: treatment (\%), FW: fresh weight (mg), \\
DW: dry weight (mg)
\end{tabular}

colors turned to have blackish at the edges of the culture by time, especially at the treatment of $1 \%, 2 \%$, and $3 \%$ sucrose concentrations (Fig. 3).

Both the fresh weight and dry weight of the callus increase gradually according to the concentration of sucrose added (Fig. 3). The highest growth index of FW and DW in 5\% sucrose treatments $(5 \mathrm{~g} / \mathrm{L}(\mathrm{w} / \mathrm{v}))$, respectively $1092.71 \pm 119.16 \mathrm{mg}$ which were not significantly different from the other 5 treatments, and $2.68 \pm 0.40 \mathrm{mg}$ which was not significantly different from the $4 \%$ sucrose experiment. In Gynura procumbens, the increase in biomass is also in line with the increase in sucrose concentration, with $5 \%$ being the most optimal concentration (Nurokhman et al., 2018). Some other studies generally recommend $3 \%$ sucrose to achieve the highest biomass, such as in Myrmecodia tuberosa (Sari et al., 2018), Digitalis lanata (Fatima et al., 2009), and Metroxylon sagu (Sumaryono et al., 2012). In this study, callus able to grow in media containing $0 \%$ sucrose until its reach stationary phase.

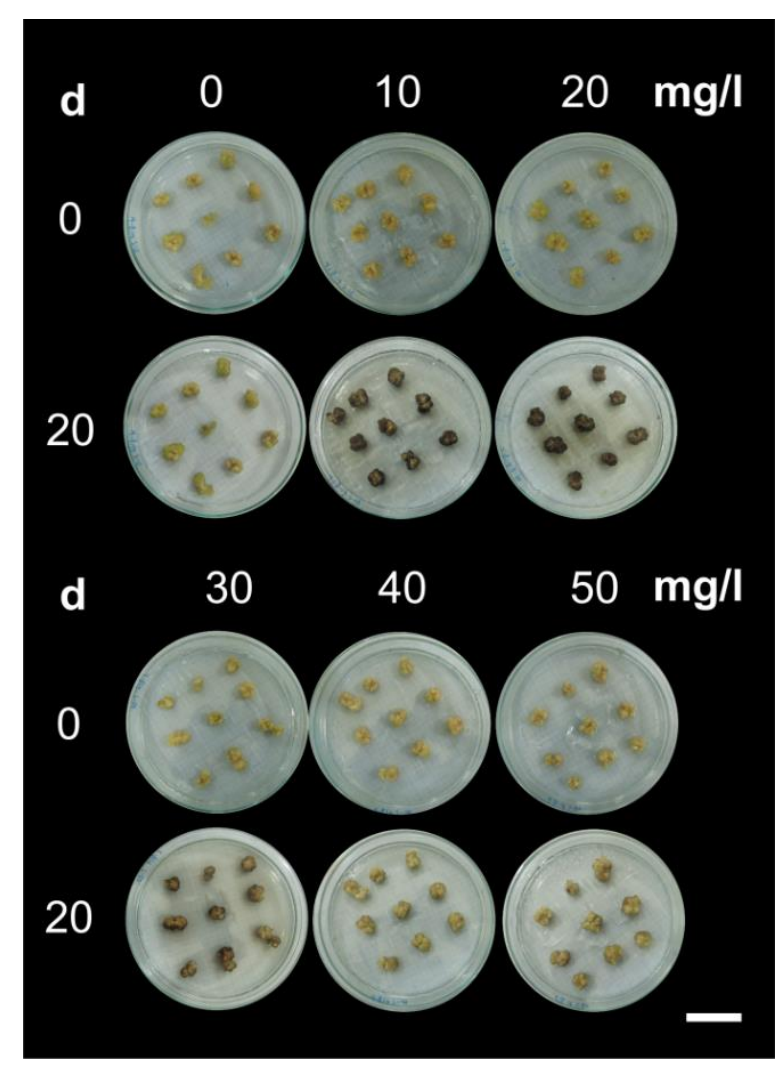

Figure 4. Variations of sucrose concentration changed the callus color and size after 20 days of treatment. Bar: $5 \mathrm{~cm}$

\section{Discussion}

Growth refers to the irreversible changes in the size of a cell as a result of division and enlargement (Hunt, 2012). In an in vitro experiment of callus induction from hypocotyl explant, seedlings germinated in fourthstrength MS medium. This medium has 3 times more water content than full-strength MS. Rapid process of imbibing water causes seeds faster to germinate.

The germination index reflects the average time needed for seeds to germinate. The speed of germination shows the average number of seeds that germinate per day. There are various factors that cause some seeds not viable, and may not depend on the medium being tested because the percentage of failure to germinate is small. Factors such as viability related to seed shelf life, extreme dehydration which causes the embryo to die, gas exchange, temperature, and light affect the success of seed germination. In tomato seeds stored for 7 years, the percentage of germination reaches $70-100 \%$, whereas if stored for 10 years 
becomes less than 30\% (Mayer \& PoljakoffMayber, 1982).

Each part of the sprouts has meristematic properties. Use cut segments of hypocotyl for explants offer some advantages in that it is the longest part of seedling (80\%) so can be providing the need for many explants and the low ability for regeneration to become organs that is more advantages for callus induction (Ali, Yossef, \& El-Banna, 2012).

The SA medium only contains sucrose. Although seedlings grow faster, this medium fails to develop cotyledons and even begins to die on the $10^{\text {th }}$ day. Sucrose initially plays a role in cell division and tracheal formation in hypocotyl, but over time sucrose also inhibits the formation of chlorophyll and photosynthesis (Gamborg et al., 1976). The absence of macro and micronutrients causes cells to be unable to continue their metabolisms, such as due to the inhibition of synthesis of various protein products, cell walls, and signaling between cells.

There are other factors that need to be considered besides the seedling growth rate, ie the biomass. This is related to how many cells can be induced into callus if cells mature rapidly due to stress on the medium with minimal nutrient availability.

In addition, this study was conducted to evaluated callus biomass after affecting different sucrose concentrations. Its value indices for the presence or absence of cell multiplication on the callus. Sucrose has been used as a major carbohydrate source in the induction medium.

Callus fresh weight is considered to represent the water uptake capacity, which actually implies that callus water mass (callus fresh weight minus callus dry weight) is proportional to callus dry weight during callus growth. In some other cases, fresh weight considered to be related to the amount of extract of the active ingredient to be harvested. While the dry weight is more to show how the ability of plants to build solid structures from their bodies.

The effect of sucrose in cells is sufficient sugar demand in cells could inhibit the process of photosynthesis (Lobo et al., 2015). On the other hand, sucrose could also cause stress on callus culture. Sucrose could be rapidly hydrolyzed to form glucose and fructose.
These process increasing the osmolality of the medium. The sucrose-treated medium may enter the plant cell through diffusion and osmosis processes. Shahnewaz \& Bari (2004) revealed that the effect of concentration of sucrose affects the increase of frequency of callus induction, which may be due to its contribution to the medium's osmotic potential rather than its use as a carbon source. This shows that the cells are stressed.

As reported by various researchers, higher sugar concentrations have a growth-inhibiting effect (Ciereszko, 2018). At higher concentrations of sucrose in the culture media, there was an increase in tissue necrosis and phenolic concentration and a sharp decline in the three sugar beet (Beta vulgaris) lines shoot regeneration (Yildiz, Onde, \& Ozgen, 2007).

Carbon sources can influence cell growth by affecting the medium's water potential. This factor is very important because the carbon sources determine the movement of mineral and water components into plant tissues and also better for turgor maintains for plant cells (Buah et al., 2011).

Vitrification could also be influenced by the carbon source used. Vitrification could increase with the decrease in the concentration of sucrose added (Wojtania, Gabryszewska, \& Podwyszyńska, 2011). Low concentrations of sucrose and sorbitol, around $0.5 \%$ and $1.5 \%$ affect the distortion of the stem with symptoms of vitrification and necrosis (Yaseen, Ahmed, Abbasi, \& Hafiz, 2009). Vitrification was less likely to influence the increase in fresh weight in the $0 \%$ sucrose treatment in this study. The deposits of sucrose from previous cultures may still support the callus to continue to multiply its cells for a period of time. Another possibility is that although chlorophyll in the callus only forms in a few areas of the surface, this is sufficient to support the ability of autotrophs and contribute to the accumulation of carbohydrates which results in an increase in biomass.

\section{Acknowledgment}

This research was supported by HKDM Faculty of Biology, Universitas Gadjah Mada (No. UGM/BI/1672/M/02/05). 


\section{References}

Ali, A., Yossef, T., \& El-Banna, A. (2012). Cytokinin-cytokinin interaction ameliorates the callus induction and plant regeneration of tomato (Solanum lycopersicum Mill.). Acta Agronomica Hungarica, 60(1), 47-55.

Arancon, N. Q., Pant, A., Radovich, T., Hue, N. V., Potter, J. K., \& Converse, C. E. (2012). Seed germination and seedling growth of tomato and lettuce as affected by vermicompost water extracts (teas). HortScience, 47(12), 1722-1728.

Chaudhry, Z., Abbas, S., Yasmin, A., Rashid, H., Ahmed, H., \& Anjum, M. A. (2010). Tissue culture studies in tomato (Lycopersicon esculentum) var. Moneymaker. Pakistan Journal of Botany, 42(1), 155-163.

Ciereszko, I. (2018). Regulatory roles of sugars in plant growth and development. Acta Societatis Botanicorum Poloniae, 87(2), 1-13.

Durosomo, H. A., Popoola, A. R., Afolabi, C. G., \& Idehen, E. O. (2014). Germination and In Vitro regeneration response of local Nigerian tomato cultivar using different explant sources. Nigerian Journal of Biotechnology, 28(1), 35-42.

Fatima, Z., Mujib, A., Fatima, S., Arshi, A., \& Umar, S. (2009). Callus induction, biomass growth, and plant regeneration in Digitalis lanata Ehrh.: influence of plant growth regulators and carbohydrates. Turkish Journal of Botany, 33(6), 393405.

Gamborg, O. L., Murashige, T., Thorpe, T. A., \& Vasil, I. K. (1976). Plant tissue culture media. In Vitro Cellular \& Developmental Biology-Plant, 12(7), 473-478.

Hana, C.A. (2016). Analysis of the dominant compound content and proteins content in tomato plants (Solanum lycopersicum L.) stem cells and antioxidant activity test (Unpublished undergraduate thesis). Universitas Gadjah Mada, Yogyakarta, Indonesia.

Hunt, R. (2012). Basic growth analysis: plant growth analysis for beginners. London, England: Springer Science \& Business Media.
Kumar, P. P., \& Loh, C. S. (2012). Plant tissue culture for biotechnology. In A., Altman \& P.M., Hasegawa (Eds.). Plant biotechnology and agriculture: prospects for the 21 $1^{\text {st }}$ century (pp. 131-138). New York, NY: Academic Press.

Lobo, A. K. M., de Oliveira Martins, M., Neto, M. C. L., Machado, E. C., Ribeiro, R. V., \& Silveira, J. A. G. (2015). Exogenous sucrose supply changes sugar metabolism and reduces photosynthesis of sugarcane through the down-regulation of Rubisco abundance and activity. Journal of Plant Physiology, 179, 113-121.

Mayer, A. M., \& Poljakoff-Mayber, A. (1982). The germination of seeds ( $3^{\text {rd }}$ Ed.). Sydney, SA: Pergamon Press.

Miastkowska, M., \& Sikora, E. (2018). Antiaging properties of plant stem cell extracts. Cosmetics, 5(4), 1-8.

Modarres, M., Bahabadi, S. E., \& Yazdi, M. E. T. (2018). Enhanced production of phenolic acids in cell suspension culture of Salvia leriifolia Benth. using growth regulators and sucrose. Cytotechnology, 70(2), 741-750.

Morus, M., Baran, M., Rost-Roszkowska, M., Skotnicka-Graca, U. (2014). Plant stem cells as innovation in cosmetics. Acta Poloniae Pharmaceutica, 71(5), 701-707.

Murashige, T., \& Skoog, F. (1962). A revised medium for rapid growth and bio assays with tobacco tissue cultures. Physiologia Plantarum, 15(3), 473-497.

Naik, P. M., \& Al-Khayri, J. M. (2016). Abiotic and biotic elicitors-role in secondary metabolites production through in vitro culture of medicinal plants. In S., Arun \& S., Chitra (Eds.). Abiotic and biotic stress in plants-recent advances and future perspectives (pp. 247-277). Rijeka: Intech.

Nurokhman, A., Tahani, N. A., Faizah, H., Utami, E. S. W., \& Wulan, Y. S. (2018). Influence of combination of sucrose concentration and immersion frequency on biomass and flavonoid production of Gynura procumbens (Lour.) Merr callus culture in temporary immersion bioreactor. Scholars Academic Journal of Biosciences, 6(12), 748-754. 
Riastri, A. (2019). Uji efek sitoprotektif ekstrak sel punca kecambah tomat (Solanum lycopersicum L.) dan analisis ekspresi sitokin TNF-Alpha pada sel Human Dermal Fibroblast Adult (HDFa) yang diinduksi sinar UV-B (Unpublished undergraduate thesis). Universitas Gadjah Mada, Yogyakarta, Indonesia.

Sari, Y. P., Kusumawati, E., Saleh, C., Kustiawan, W., \& Sukartiningsih, S. (2018). Effect of sucrose and plant growth regulators on callogenesis and preliminary secondary metabolic of different explant Myrmecodia tuberosa. Nusantara Bioscience, 10(3), 183-192.

Schmid, D., Schurch, C., Blum, P., Belser, E., \& Zulli, F. (2008). Plant stem cell extract for longevity of skin and hair. Journal Seifen Ole Fette Wachse, 134(5), 30-35.

Shahnewaz, S., \& Bari, M. A. (2004). Effect of concentration of sucrose on the frequency of callus induction and plant regeneration in anther culture of rice (Oryza sativa L.). Plant Tissue Culture, 14(1), 37-43.

Skoog, F., \& Miller, C. (1957). Chemical regulation of growth and organ formation in plant tissues cultured. Symposia of the Society for Experimental Biology, 11, 118-30.

Smith, R. H. (2012). Plant tissue culture: techniques and experiments ( $3^{\text {rd }}$ Ed.). London, England: Academic Press.

Sumaryono, S., Muslihatin, W., \& Ratnadewi, D. (2012). Effect of carbohydrate source on growth and performance of In Vitro sago palm (Metroxylon sagu Rottb.) plantlets. HAYATI Journal of Biosciences, 19(2), 88-92.

VanderMolen, K. M., Raja, H. A., El-Elimat, T., \& Oberlies, N. H. (2013). Evaluation of culture media for the production of secondary metabolites in a natural products screening program. $A M B$ Express, 3(1), 1-7.

Wojtania, A., Gabryszewska, E., \& Podwyszyńska, M. (2011). The effect of growth regulators and sucrose concentration on in vitro propagation of Camellia japonica L. Propagation of Ornamental Plants, 11(4), 177-183.

Yaseen, M., Ahmed, T., Abbasi, N. A., \& Hafiz, I. A. (2009). In vitro shoot proliferation competence of apple rootstocks M. 9 and M. 26 on different carbon sources. Pakistan Journal of Botany, 41(4), 1781-1795.

Yildiz, M., Onde, S., \& Ozgen, M. (2007). Sucrose effects on phenolic concentration and plant regeneration from sugarbeet leaf and petiole explants. Journal of Sugar Beet Research, 44(1), 1-15. 